This item was submitted to Loughborough's Research Repository by the author.

Items in Figshare are protected by copyright, with all rights reserved, unless otherwise indicated.

\title{
Targeting environmental factors to reduce elderly in-patient falls
}

PLEASE CITE THE PUBLISHED VERSION

http://www.ahfe2010.org/

PUBLISHER

AHFE 2010

VERSION

VoR (Version of Record)

LICENCE

CC BY-NC-ND 4.0

REPOSITORY RECORD

Hignett, Sue, Gina Sands, Jane Youde, and Paula L. Griffiths. 2019. "Targeting Environmental Factors to Reduce Elderly In-patient Falls”. figshare. https://hdl.handle.net/2134/7463. 
This item was submitted to Loughborough's Institutional Repository (https://dspace.lboro.ac.uk/) by the author and is made available under the following Creative Commons Licence conditions.

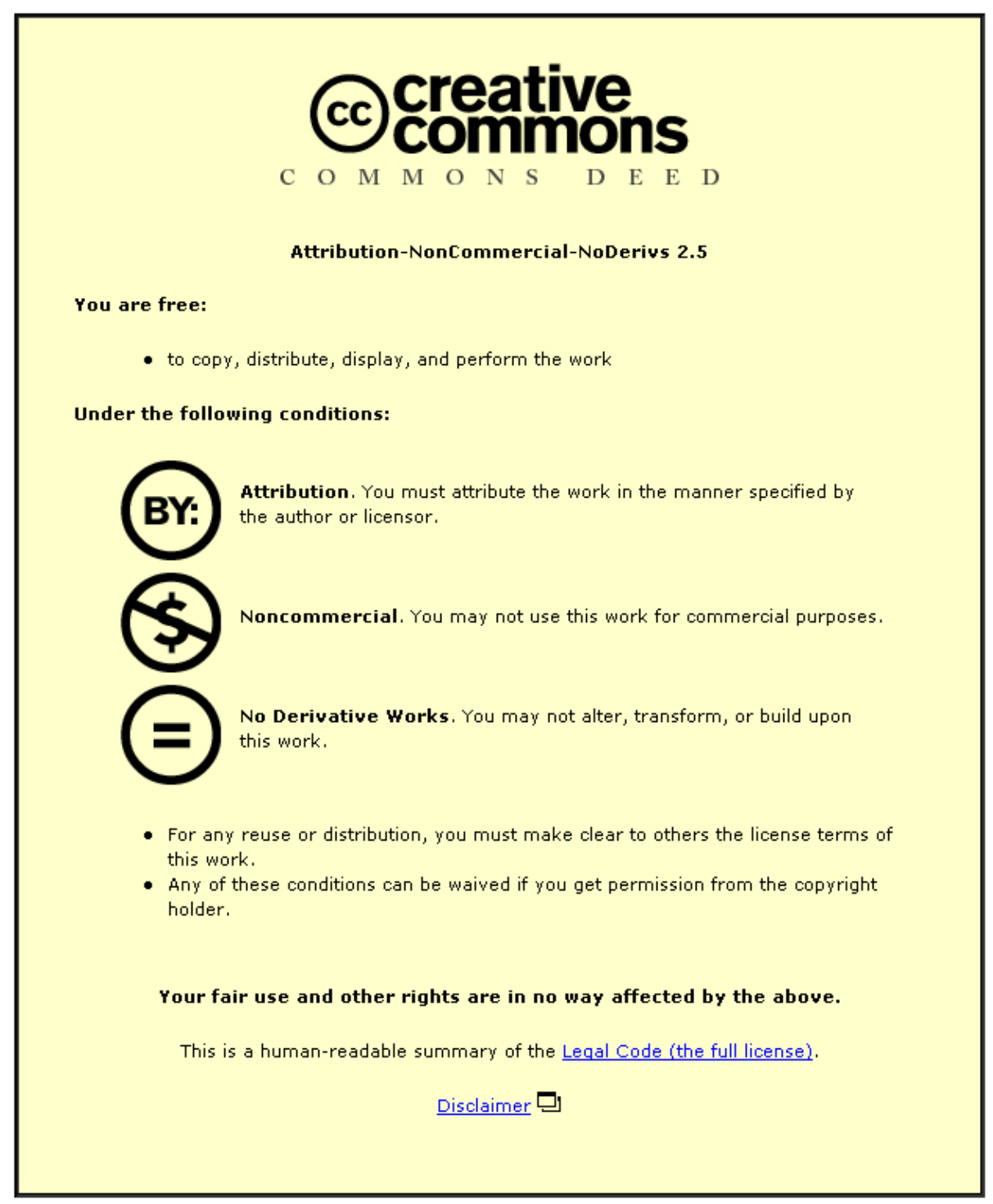

For the full text of this licence, please go to: http://creativecommons.org/licenses/by-nc-nd/2.5/ 
Proceedings of the 1st International Conference on Human Factors and Ergonomics in Healthcare, $3^{\text {rd }}$ International Conference on Applied Human Factors and Ergonomics 17-20 July 2010, Miami, USA

\title{
Targeting E nvironmental Factors to R educe E Iderly In-Patient Falls
}

\author{
Sue Hignett ${ }^{1}$, Gina Sands ${ }^{1}$, J ane Youde ${ }^{2}$, Paula G riffiths ${ }^{1}$ \\ ${ }^{1}$ L oughborough University \\ ${ }^{2}$ D erby H ospitals NHS Foundation Trust
}

\begin{abstract}
This paper will describe the results from two exploratory studies on un-witnessed elderly in-patient falls in acute facilities. The first study analyzed incident reports from England and Wales between 1 September 2006 and 31 August 2007 $(n=215,784)$. We found a difference in the location of falls for patients described as frail and those described as confused. This was further explored in a pilot study to collect detailed information about contributory factors and the location of falls through staff interviews. We found that the use of bedrails seemed to alter the location of the fall, with falls from beds with raised rails clustered around the foot end of the bed.
\end{abstract}

\section{INTRODUCTION}

In-patient falls have consistently been the biggest single category of reported incidents from since the 1940s; they are a significant cause of morbidity and mortality and have a high prevalence after admission to hospital (M organ et al, 1985; Oliver et al, 2004; M ahoney, 1998). The risk factors have been identified and reported since the 1950s (Parrish and Weil, 1958; Fine, 1959; Fagin and Vita, 1965). A lthough only a small percentage of patient falls result in death and serious injury they represent a serious financial, governance and resource burden in terms 
of on-going healthcare costs and litigation (B oushon et al., 2008). The incident rate for falls is approximately three times higher in hospitals and nursing homes than in community-dwelling older people (A merican Geriatrics Soci ety, 2001). It has been suggested that this may be due to a combination of extrinsic risk factors (relating to the environment), for example, unfamiliar environment and wheeled furniture, combined with intrinsic risk factors (relating to the patient) such as confusion, acute illness and balance-affecting medication (Tinker, 1979; Tinetti, 2003; Sal gado et al, 2004; Kannus et al, 2006). M any papers have reported that the majority (over $70 \%$ ) of in-patient falls are un-witnessed with the patient found on the floor and little information in the incident report. (Fagin and V ita, 1965; Hitcho et al, 2004; Healey et al, 2008).

This paper offers an exploration of contributory factors with a detailed analysis of falls risks from reported incidents and a pilot case study of unwitnessed in-patient falls on Care of the Elderly wards in an acute hospital.

\section{METHOD}

215,784 reports were retrieved from the UK National Reporting and Learning System (NRLS) database for slips, trips and falls between 1 September 2006 and 31 August 2007, with 44,202 reports from Care of the Elderly wards in acute and community hospitals in England and Wales. A random 15\% sample was taken $(6,577$ reports), of which 4,571 were un-witnessed. The free text narratives on the incident reports were coded into intrinsic and extrinsic contributory factors using an initial conceptual framework (Hignett and Masud, 2006). As coding progressed more factors emerged from the data and were added to the coding framework. All the reports were re-coded with the final set of factors to ensure inclusivity of the coding process. Reports were coded as frail if the patient was described as weak, frail or needing a walking aid, and as confused if described as having any type of dementia, confusion or lack of awareness. As most falls were the result of a combination of factors, few were coded to a single code. The contributory risk factors for the frail and confused groups were compared with the whole sample and explored with the Chi-squared and Fisher's exact tests. The effect size was calculated to determine the strength of the relationships using the Phi statistic and statistical significance was assessed with a two-tailed P-value $<0.05$.

The pilot case study reviewed 26 reported incidents for un-witnessed patient falls from $M$ arch to September 2009 in 4 Care of the Elderly wards $(n=112)$ in a large acute hospital (1,150 beds). The nurse reporting the incident was interviewed with a structured proforma (figure 1) to add factual information, for example the exact location of the fall, whether the bed rails were raised (3/4 length rails) and the type of footwear worn by the patient at the time of the fall. The study was granted Ethical A pproval from Nottingham Research Ethics Committee 1 (08/H0403/149) and Research Governance by Royal Derby Hospital (DHRD/2008/071). 
Where was the patient before they fell?

Where was the patient found?

Were the bed rails up or down?

Were they using a mobility aid (e.g. stick, frame, wheelchair)?

Were they wearing slippers or shoes?:

What was the flooring?

What was the lighting level?

Does the patient use glasses? W ere they wearing glasses?

W as the patient attached to anything e.g. catheter, drip?

What happened after the fall?

How did the patient get up from the floor?

Were anv iniuries cı ctained?

FIGURE 1 Interview Proforma

\section{RESULTS}

A nalysis of the NRLS revealed that most falls occurred at the bedside $(n=1,726)$, with 416 patients reported to have fallen in the bathroom. 356 patients were coded as frail, 481 as confused, and 3,814 reports had insufficient information to code these factors. The highest number of reported intrinsic and extrinsic risks were toilet-related ( $n=508$; e.g. incontinence), bed rails up $(n=230)$ and slippery/wet floor ( $n=121$ ). The location of falls (figure 2 ) indicated that more than the expected number of frail patients fell in the toilet/bathroom $(17 \%, n=62$, expected $n=32.4)$. Less than the expected number of frail patients fell by the bed $(23 \%, n=81$, expected. $n=134.4$ ) and less than the expected number of confused patients fell in the toilet/bathroom ( $5 \%, n=24$, expected. $n=43.8)$.

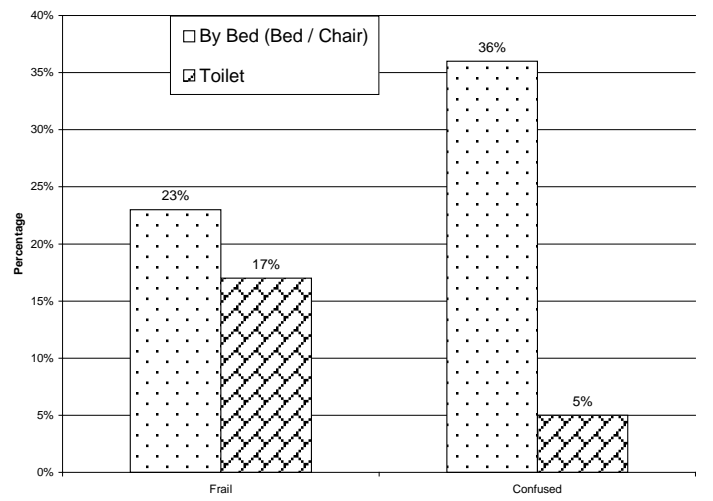

FIGURE 2 Incident data analysis 
The case study also found that most patients fell by the bed $(n=18)$, with 5 falling from an adjacent chair or commode, and 3 falling in the bay or bathroom. 18 patients were found on the floor by the bed, 4 were found by their chair, 3 in the middle of the bay and 1 in the bathroom (figure 3). 10 of the 18 patients falling from bed had raised bed rails; for 7 patients bed rails were either not applicable as they were not in bed or there was no information. M ost patients had bare feet $(n=17)$ at the time of the fall, with 8 wearing shoes, socks or slippers. 14 falls occurred under 'good lighting' (day light or artificial light), with 12 falls in poorly lit conditions

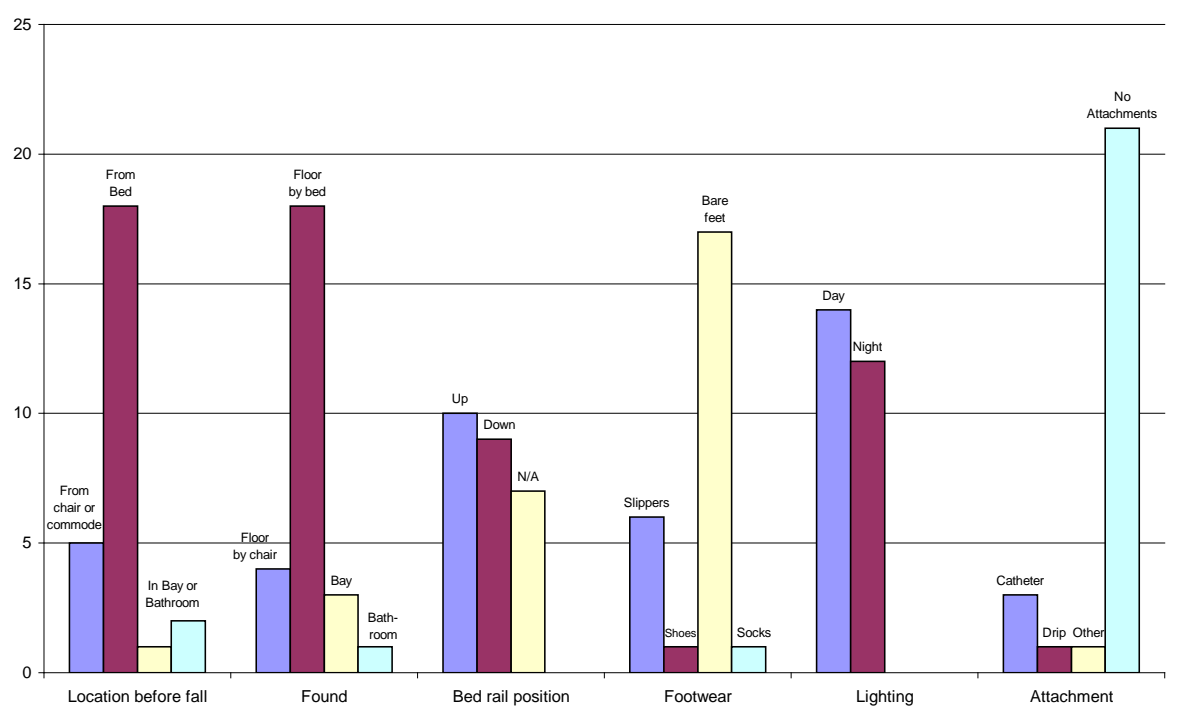

FIGURE 3 Case study results

The data were plotted on three location maps (figures 4, 5 and 6). In the 10 cases the falls occurred from the bed when the bedrails were raised (figure 4), with the patient found on the floor at the lower end of the bed, having 'wriggled to the bottom' of the foot end of the bed.

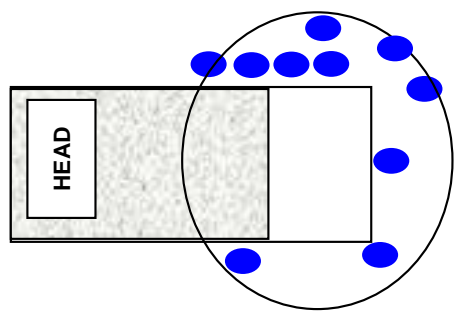

FIGURE 4 Location map of falls from the bed with raised bed rails 
In the 8 cases the falls occurred from the bed when the bedrails were not raised (figure 5). The location of the falls is less clustered than figure 4 (with raised bedrails).

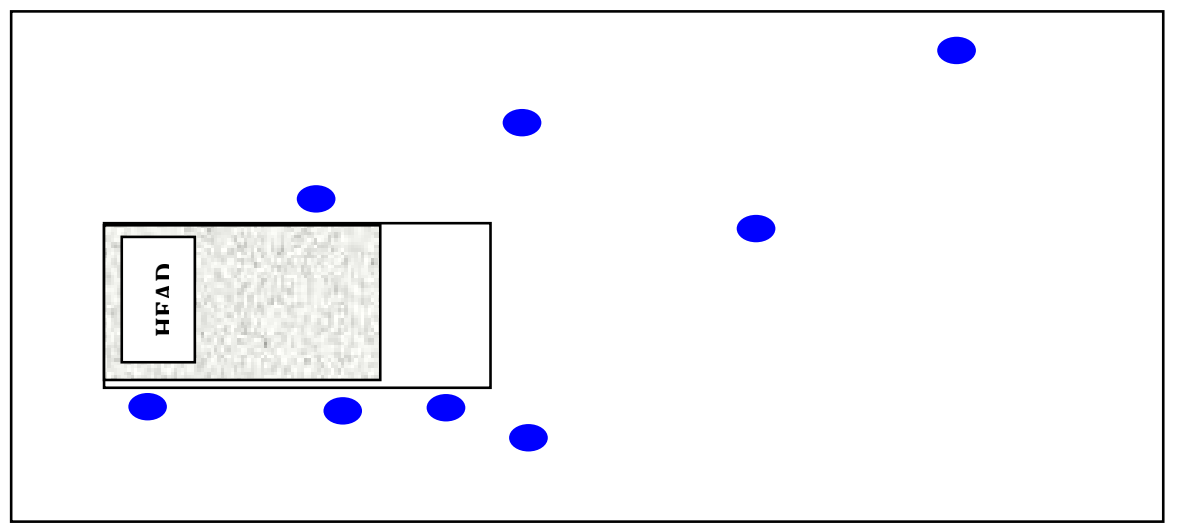

FIGURE 5 Location map of falls from the bed with no bed rails

In 5 cases where the patient fell from a chair or a commode they were found on the floor by the head of the bed $(n=4)$ or at the end of the bed $(n=1)$. Three other patients were found in the middle of the bay and in the bathroom (figure 6).

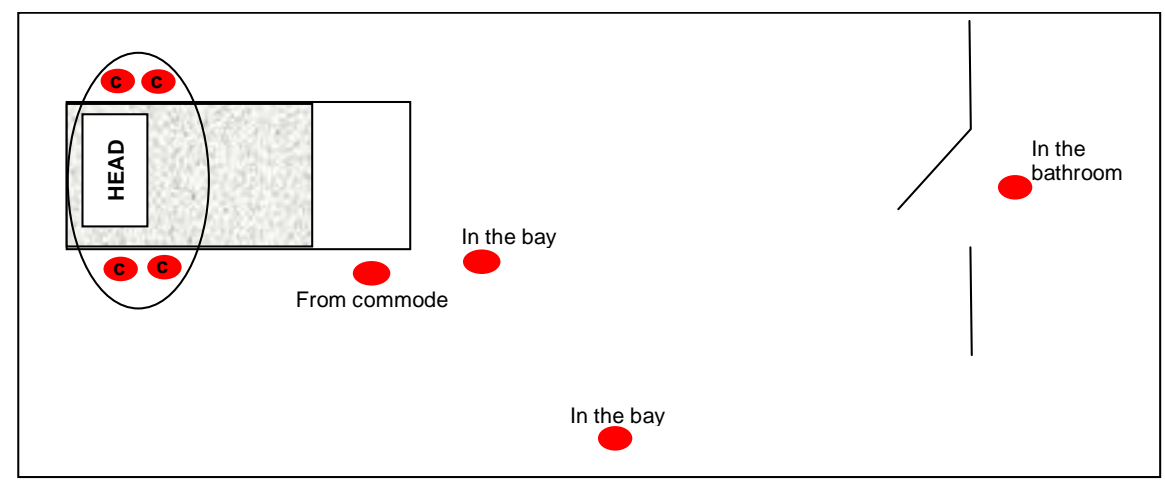

FIGURE 6 Location map of falls from chair/commode or in the bay/bathroom 


\section{DISCUSSION AND CONCLUSION}

Although the statistical effect size for the NRLS associations was small and this analysis does not allow us to show causal relationships, some interesting issues have emerged that require further investigation, for example bed rails and location of the fall. The use of bed rails has been discussed since the 1960s, with Fagin \& Vita (1965) commenting that 'to many conscious patients, side rails are frightening and imply dangerous illness. To others, side rails are irritating and humiliating because they emphasize the confining aspects of hospitalization.' Bed rails have been used extensively as an intervention to manage falls (MCCarter-Bayer et al., 2005; Capezuti et al., 2007; Hanger et al, 1999; Healey et al., 2004), but there is no evidence that they prevent falls or injury (Capezuti et al., 2007; Hanger et al., 1999).

The location of falls suggest that patients described as frail were able to achieve a greater distance from the bed (possibly with a walking aid), with a higher than expected number reported to have fallen in the toilet/bathroom. Interventions to address elimination needs have included scheduled toileting (K ilpack et al, 1991; $\mathrm{K}$ rauss et al, 2008). This has reported limited success for two-hourly schedules due to poor patient compliance ( $\mathrm{K}$ rauss et al, 2008), although a pilot trial indicated that hourly rounding may reduce the number of falls (M eade et al, 2006). In 1987 Morse et al. reported a study where patients were interviewed about contributory factors for falls. Patients identified difficulties with distance perception (frequently underestimating distances between objects) due to the greater size and distance between hospital fixtures compared to those at home. There have been several interventions to facilitate the route from bed-to-bathroom. These include bringing the toilet to the bed by placing the commode adjacent to the bed ( $\mathrm{K}$ rauss et al., 2008; Chung, 2009), locating the patient in a bed near to toilet in multi-bed bays (Parker, 2000; K rauss et al., 2008; J anken et al., 1986), removing obstacles from the bed-toilet pathway (K rauss et al., 2008; Becker et al., 2003; Ray et al., 1997; SeminGoossens et al., 2003), and marking a path from the bed to the bathroom (West, 2009 personal communication).

It has been suggested that changes in hospital design may affect the risk of falls (Gulwadi \& Calkins, 2008; Janken et al., 1986; Feldbauer et al, 2008) but research studies have failed to systematically evaluate environmental design interventions. The lack of high quality research on physical environment interventions might be, as Oliver et al. (2007) suggest due to the 'inherent logistic difficulties in performing or interpreting studies in care homes or hospitals associated with population, setting, design, and outcome measurement. G etting consent from or randomizing 
frail, confused, unwell elderly people, who are often in the institution for only a short stay, is challenging'.

In the US, falls resulting in patient death or serious disability while being cared for in a healthcare facility are included in the 28 'never event' categories by the National Quality Forum (2007) and Institute for Healthcare Improvement (2008). This is likely to raise the priority for finding effective interventions as it is an emerging belief that hospitals may not be reimbursed for events that should never occur, this would include falls (Odom-Forren, 2008).

$M$ aking environmental changes can be very expensive. If the research evidence is not available to show that different layouts and technology can reduce both the incidents and injuries associated with elderly in-patient falls at the time of construction then retro-fitting is unlikely to happen.

\section{REFERENCES}

A merican Geriatrics Society. (2001), "Guideline for the Prevention of Falls in Older Persons." J ournal of the American G eriatrics Society, 49(5), 664-672.

Becker, C., K ron, M., Lindemann, U., Sturm, E., Eichner, B., W alter-J ung, B. et al. (2003), "E ffectiveness of a multi-faceted intervention on falls in nursing home residents." J ournal of the American G eriatrics Society, 51, 306-13.

B oushon, B., Nielsen, G., Quigley, P., Rutherford, P., Taylor, J., Shannon, D. (2008), Transforming Care at the Bedside How-to-Guide: Reducing Patient Injuries from $\mathrm{F}$ alls. Cambridge, M A Institute for Healthcare Improvement.

Capezuti, E., Wagner, L.M., Brush, B.L., B oltz, M., Renz, S., Talerico, K.A. (2007), "Consequences of an intervention to reduce restrictive side rail use in nursing homes." J ournal of the American Geriatrics Society, 55(3), 334-41.

Chung, H. (2009), The lived experience of older adults who fall during hospitalization. PhD Dissertation. College of Nursing, Graduate School of the Texas Woman's University

Fagin, I.D., Vita, M. (1965) "Who? Where? When? How? A n A nalysis Of 868 Inpatient A ccidents." H ospitals 39:60-5.

Feldbauer, R., Boan, D., Nadzam, D., Finis, N., Nadzam, B. (2008), “D esign of a patient-safe environment: The Joint Commission Position." HERD, 1(2), 65-68.

Fine, W. (1959), "An analysis of 277 falls in hospitals." Gerontological Clinics, 1, 292-300.

Gulwadi, G.B., Calkins, M .P. (2008), "The Impact of Healthcare Environment Design on Patient Falls." The C enter for H ealth D esign. www.healthdesign.org 
Hanger, H.C., Ball, M .C. Wood, L.A. (1999), "An A nalysis of Falls in the Hospital: Can We Do W ithout Bedrails?" J ournal of the American Geriatrics Society, 47(5), 529-531.

Heal ey, F., M onro, A., Cockram, A., A dams, V., Heseltine, D. (2004). “Using targeted risk factor reduction to prevent falls in older in-patients: a randomised controlled trial." Age and Ageing, 33, 1-5

Heal ey F, Scobie S, Oliver D, Pryce A, Thompson R, Glampson B. (2008), "Falls in English and W elsh hospitals: a national observational study based on retrospective analysis of 12 months of patient safety incident reports." Q uality and Safety in Healthcare 17:424-430.

Hignett, S. M asud, T. (2006), A R eview of Environmental Hazards associated with In-Patient Falls. Ergonomics, 49(5-6), 605-616.

Hitcho E, Krauss M, Birge S, Dunagan W, Fischer I, J ohnson S. et al (2004) "Characteristics and circumstances of falls in a hospital setting." J ournal of General Internal M edicine 19:732-739.

Institute for Healthcare Improvement (2008), IHI Global Trigger Tool for M easuring Adverse E vents (UK Version). Cambridge M A : Institute for Healthcare Improvement

Janken, J.K., Reynolds, B.A ., Swiech, K. (1986), "Patient falls in the acute care setting: identifying risk factors." Nursing Research, 35(4), 215-9.

K annus, P., K han, K.M., Lord, S.R. (2006), "Preventing falls among elderly people in the hospital environment." M edical J ournal of Australia, 184(8), 372-3.

Kilpack V , B oehm J, Smith N, M udge B. (1991), "Using research-based interventions to decrease patient falls." Applied Nursing Research, 4(2), 50-56.

K rauss M J , Tutlam N, Costantinou E, J ohnson S, Jackson D, Fraser V J. (2008), "Intervention to prevent falls on the medical service in a teaching hospital." Infect Control Hosp E pidemiol, 29(6), 539-45.

M ahoney, J.E. (1998), Immobility and Falls. C lin Geriatr M ed, 14(4), 699-727.

M cCarter-Bayer, A., Bayer, F., Hall, K. (2005), "Preventing falls in acute care." J ournal of Gerontological Nursing, 31(3), 25-33.

M eade CM , B ursell AL, K etelsen L. (2006), "E ffects of Nursing Rounds on patients' call light use, satisfaction and safety." A merican J ournal of N ursing, 106(9), 5870.

M organ, V .R., M athison, J.H., Rice, J.C., Clemmer, D.I. (1985), “Hospital falls: a persistent problem." Am J Public Health, 75(7), 775-777.

M orse, J.M., Tylko, S.J., Dixon, H.A. (1987), "Characteristics of the Fall-Prone Patient." The Gerontologist, 27(4), 516-522.

National Quality Forum (2007), Serious Reportable E vents in Healthcare 2006 U pdate. A Consensus Report. W ashington DC: National Quality Forum 
Odom-Forren, J. (2008), "Never Events: A Patient Safety Imperative." J ournal of PeriAnaesthesia Nursing, 23(4), 223-225.

Oliver, D., Daly, F., M artin, M., M CM urdo, M. (2004), "Risk Factors and risk assessment tools for falls in hospital inpatients: a systematic review." Age Ageing, 22, 122-130.

Oliver, D., Connelly, J B., Victor, C.R., Shaw, F.E., Whitehead, A., Genc, Y . et al. (2007), "Strategies to prevent falls and fractures in hospitals and care homes and effect of cognitive impairment: systematic review and meta-analyses." BMJ , 334, 82-7.

Parker, R. (2000), "A ssessing the risk of falls among older patients." Professional Nurse, 15(8), 511-514

Parrish, H., W eil, T .P. (1958), "Patient A ccidents Occurring in Hospitals: Epidemiologic study of 614 accidents." New York State J ournal of M edicine, 58(6), 838-846.

Ray, W .A., Taylor, J.A., M eador, K.G., Thapa, P.B., Brown, A.K., Kajihara, H.K. et al. (1997), "A randomized trial of a consultation service to reduce falls in nursing homes." J AM A, 278(7), 557-62.

Sal gado, R.I., L ord, S.R., Ehrlich, F., Janji, N., Rahman, A . (2004), "Predictors of falling in elderly hospital patients." Archives of Gerontology and Geriatrics, 38, 213-219.

Semin-Goossens, A ., van der Helm, J.M .J., Bossuyt, P.M.M . (2003), "A failed modelbased attempt to implement an evidence-based nursing guideline for fall prevention." J Nurs Care Qual, 18(3), 217-225.

Tinetti, M. (2003), "Clinical practice; Preventing falls in elerly persons." New England J ournal of M edicine, 348(1), 42-49.

Tinker, G.M . (1979), "A ccidents in a Geriatric Department." Age Ageing, 8(3), 196198. 